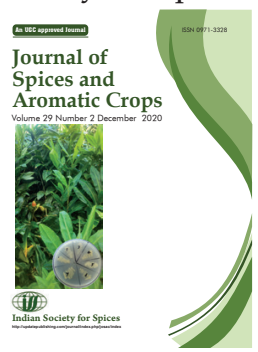

\title{
Morphological characterization and secondary metabolites profile of black pepper (Piper nigrum L.) genotypes from Sikkim
}

\author{
K Gurung* \& S Manivannan \\ Department of Horticulture, School of Life Science, \\ Sikkim University, Tadong-737 102, Sikkim. \\ *E-mail: gurungnee08@gmail.com
}

Received 14 July 2020; Revised 16 October 2020; Accepted 05 November 2020

\begin{abstract}
Quantification of volatile oil and analysis of four major metabolites using HPLC was done in 24 black pepper genotypes collected from south Sikkim. The amount of volatile oil ranged from $2.01 \%$ to $0.022 \%$. Secondary metabolites like piperine ranged from $2.75-0.022 \%$, myrcene from $2.094-0.022 \%$, alpha- phellandrene from $1.373-0.008 \%$ and linalool from $0.834-0.012 \%$. Genotype 23 had the highest amount of myrcene and linalool, genotype 13 had the highest quantity of piperine and genotype 8 had high amount of alpha-phellandrene. The principal component analysis (PCA) of analyzed metabolites grouped the genotypes into four categories. The study revealed that some of the genotypes were as good as pepper varieties grown in traditional areas. These genotypes will be useful in crop improvement strategies and suitable for Sikkim Himalaya.
\end{abstract}

Keywords: black pepper, volatile oil, HPLC, metabolites

\section{Introduction}

Black pepper (Piper nigrum) is a perennial vine grown for its berries extensively used as spice and in medicine and belongs to the family Piperaceae (Bentham et al. 1980). The genus Piper is distributed in tropical and subtropical regions of the world. The main centers of distribution are central and south America and South Asia (Trelease et al. 1950). The black pepper of commerce comprises the dried fruits of this perennial climbing vine, which is indigenous to Western Ghats of south India. Wild forms of pepper are still found growing in the rich, moist and humus soils of sub mountainous tract of this region.
Morphological parameters of pepper such as spike length varies to a great extent among cultivars.

Active compound of black pepper, is piperine (1-piperoylpiperidine). The phytoconstituents of $P$. nigrum fruits include other minor alkaloids such as piplartin, piperlogumine, piperidine, starch and resin. Piperine is an alkaloid found in the fruits and roots of piper species of piperaceae family. Piperine along with chavicine an isomer of piperine is responsible for the pungency of $P$. nigrum. Piperine is the main phytochemical responsible for analgesic action of pepper. It has anti-inflammatory and antioxidant property. 
In Sikkim, black pepper is found mostly in the lower belts of south district because of the climatic condition that favors the growth and development of the crop. Black pepper, being a non commercial crop in Sikkim is mostly neglected. As it is in great demand due to its medicinal properties, assessing the quality parameters including the metabolites present in the genotypes of Sikkim will act an effective tool to compare them with the varieties grown in south India, which is the traditional region of black pepper cultivation. As high performance liquid chromatography (HPLC) is an efficient analytic method to ensure quality and consistency in final product, it was used to isolate, identify and quantify constituents of $P$. nigrum in our study.

Therefore, the research work was carried on the morphological and metabolic profiling of black pepper genotypes grown in Sikkim to identify various active compounds present in the pepper and to compare them with the secondary data on yield and quality parameters of varieties from traditional growing area.

\section{Materials and methods}

The sample (berries of P. nigrum) was collected from south district of Sikkim. Twenty four cultivated genotypes were collected from different locations (Table 1). The age of the vines ranged from 9 to 21 years. Yield parameters such as spike length, number of flowers spike ${ }^{-1}$, fruit set percentage and weight of fresh and dried berries were recorded.

\section{Extraction of volatile oil and isolation of metabolites}

The collected berries were sun dried and powdered. The volatile oil of these genotypes was extracted using a volatile oil extractor, (Scocsplus-SES 06 DLS, PELICAN, India).

The volatile oil extracted from the berries was mixed with methanol and the solution was then possed through a syringe filter $(0.22 \mu \mathrm{m})$ to filter out the minute particles which may get adhered to the column of HPLC. With the help of a $2 \mathrm{ml}$ syringe the oil was transferred into $2 \mathrm{ml}$ amber colored vial. In the same manner standards were prepared. The chromatography was performed in HPLC (Aligent Series 1100, Aligent Technologies, U.S.A). The mobile phase consisted of water (A) and acetonitrile (B) in the ratio of 10:90 v/v. The flow rate was $1 \mathrm{ml} \mathrm{min}{ }^{-1}$, the column used was C18 and the concentrations of different compounds present in oil of black pepper were determined using external standards.

\section{Statistical analysis of data}

For all the parameters observed, standard deviation was estimated to compare the different genotypes and to compare with the secondary data of varieties from traditional area. For secondary metabolites comparison principal component analysis (PCA) was carried out using JMP PRO 11 software.

\section{Results and discussion}

\section{Morphological and yield parameters}

In the present study, the spike length (Table 2) of the genotype 16 was longest with $13.5 \mathrm{~cm}$ followed by genotype 7 and 19 with $10.5 \mathrm{~cm}$. On the other hand genotype 6 and 24 had the shortest spike with $6.8 \mathrm{~cm}$ followed by genotype 13 with $7 \mathrm{~cm}$. Sasikumar et al. (2007) and Rmili et al. (2014) reported that the spike length was $8.33 \mathrm{~cm}$ in the unique accession "Agali", while Krishnamurthy et al. (2013) reported it as 10.3 $\mathrm{cm}$. Prasannakumari et al. (2001) reported that the spike length was $14.70 \mathrm{~cm}$ in variety Neelamundi, $13.88 \mathrm{~cm}$ in Panniyur 1 and 15.25 $\mathrm{cm}$ in Perumkody. The comparison revealed that the highest spike length observed in conventional area was $15.25 \mathrm{~cm}$ and lowest was $8.33 \mathrm{~cm}$. It is informed that the spike length of some genotypes collected in the present study lies between the earlier recorded range.

The number of flowers spike ${ }^{-1}$ was counted manually and was found to be the highest in the genotype 18 and 2 with 120 flowers, followed by genotype 8 with 105 flowers (Table 2). The lowest was found to be in genotype 22 with 
40 flowers followed by genotype 12 with 42 flowers. Prasannakumari et al. (2001) reported that the flowers spike ${ }^{-1}$ in variety Neelamundi was 96.30 and 33.80 in local variety found in Thodupuzha taluk. This indicates that the some of the accessions collected in the present study was superior in terms of number of flowers spike ${ }^{-1}$.

The fruit set was the highest in the accession 18 with $75.90 \%$, followed by genotype 14 and 2 with $75.00 \%$ (Table 2). The lowest fruit set was found in the genotype $12(52.38 \%)$, followed by genotype $6(53.96 \%)$. The fruit set was $80.2 \%$ in variety Karimunda (Chen 2013). This indicates that the best genotype used for the present study was slightly inferior to the best variety of traditional area in terms of fruit set percentage.

The weight of 100 dried berries was found more in accession 19 with $4.2 \mathrm{~g}$ and the least was observed in genotype 5 with $1.5 \mathrm{~g}$ (Table 2 ). These results were in close conformity with the findings of Krishnamurthy et al. (2013) that the weight of dried berries was around 3.8 g. Prasannakumari et al. (2001) reported the weight of dries berries were 1.160 $\mathrm{g}$ in variety Karimunda. This indicates that some of the genotypes used in the present study were slightly superior in terms of weight of dried berries as compared to the findings of Krishnamurthy et al. (2013) and Prasannakumari et al. (2001).

\section{Volatile oil and Secondary metabolites}

The highest amount of volatile oil was observed in the genotype $8(2.01 \%)$ followed by genotype $21(1.8 \%)$. Lowest amount was observed in genotype 14 with $0.16 \%$, followed by 17 with $0.22 \%$. Rmili et al. (2014) reported that the yield of volatile oil content derived from the dried berries of black pepper using a micro-assisted hydro distillation was $1.5 \%$. Shruti et al. (2013) also found that the amount of volatile oil in black pepper variety Panniyur 1 was $3.2-1.6 \%$. Singh et al. (2010) found that the volatile oil of $P$. nigrum to be $1.76 \%$ using GC-MS analysis. In our present study, the amount of volatile oil varied from 2.01 to $0.16 \%$. Therefore the genotype 8 and 20 can be explored for high volatile oil extraction.

The percentage values of $\alpha$-phellandrene varied from $1.37 \%$ to $0.08 \%$. The highest amount of $\alpha$-phellandrene was found in the genotype 8 with $1.37 \%$, followed by genotype 14 with $0.358 \%$. Likewise the lowest amount was observed in genotype 17 with $0.008 \%$, followed by the genotype 18 with $0.011 \%$. Shahin et al. (2012) reported $2.87 \%$ of $\alpha$-phellandrene content in P. nigrum. Shruti et al. (2013) analyzed the volatile oil using GC-MS that resulted in 1.04\% of $\alpha$-phellandrene in the variety Panniyur 1 . Jirovetz et al. (2002) reported that the content of $\alpha$-phellandrene was $8.56 \%$. This indicated that the genotypes used in the present study was as good as commercial variety such as Panniyur 1 in terms of $\alpha$-phellandrene content. However, the concentration range of $\alpha$-phellandrene was in the range of $1.04 \%$ to $8.56 \%$ in traditional areas. It showed that the genotypes of Sikkim have less amount of $\alpha$-phellandrene.

The percentage values of myrcene varied from $0.022 \%$ to $2.094 \%$. The highest amount of myrcene content was found in the accession $23(2.094 \%)$ followed by accession 9 (1.223\%). On the contrary, the lowest amount was found in accession $2(0.22 \%)$ followed by accession $17(0.031 \%)$. Shahin et al. (2012) found that myrcene content was $2.89 \%$ using GC-MS analysis. Shruti et al. (2013) reported that myrcene content was $1.78 \%$ to $2.28 \%$ using GC-MS. Jirovetz et al. (2002) reported that the amount of myrcene in P. nigrum was $1.38 \%$ by GC-flame ionization detection (FID) and GC-MS methods. In the present study, the myrecene content varied from $0.02 \%$ to $2.09 \%$, which was less than the findings of Shahin et al. (2012) and Shruthi et al. (2013). However, the accession 23 used in the present study can be a potential source of myrcene in future.

Linalool content varied from $0.012 \%$ to $0.834 \%$ with highest in the genotype 23 (0. 834\%) followed by genotype $24(0.789 \%)$. The least amount of linalool was present in genotype 1 
Table 1. Location details of genotypes used in the study

\begin{tabular}{|c|c|c|c|c|}
\hline Genotype & Place & Latitude & Longitude & $\begin{array}{l}\text { Altitude } \\
\text { (m MSL) }\end{array}$ \\
\hline 1 to 4 & Belbotey & $\mathrm{N} 27^{0} .07 .074$ & $\mathrm{E}^{2} 88^{0} .20 .273$ & 686 \\
\hline 5 to 8 & Lower Kitam & $\mathrm{N} 27^{0} .07 .380$ & E088 .21 .118 & 718 \\
\hline 9 to 12 & Kitam bazaar & $\mathrm{N} 27^{0} .07 .304$ & E088 .20 .880 & 843 \\
\hline 13 to15 & Suntaley & $\mathrm{N} 27^{0} .07 .543$ & E088 .27 .056 & 624 \\
\hline 16 to 18 & Lower Suntaley & $\mathrm{N} 27^{0} .07 .429$ & E088 .27 .062 & 624 \\
\hline 19 to 20 & Karfectar & $\mathrm{N} 27^{0} .09 .219$ & E088 .17 .989 & 609 \\
\hline 21 to 22 & Chisopani & $\mathrm{N} 27^{0} .09 .507$ & E088 .18 .090 & 613 \\
\hline 23 to 24 & $4^{\text {th }}$ mile & $\mathrm{N} 27^{0} .08 .874$ & E088 .17 .842 & 696 \\
\hline
\end{tabular}

Table 2. Yield characteristics of the genotypes

(Values are Mean \pm SE)

\begin{tabular}{cccccc}
\hline Genotype & $\begin{array}{c}\text { Spike length } \\
(\mathrm{cm})\end{array}$ & $\begin{array}{c}\text { Weight of fresh } \\
\text { berries }(\mathrm{g})\end{array}$ & $\begin{array}{c}\text { Weight of dried } \\
\text { berries }(\mathrm{g})\end{array}$ & $\begin{array}{c}\text { No. of flowers/ } \\
\text { spike }\end{array}$ & Fruit set (\%) \\
\hline 1 & $9.8 \pm 0.208$ & $12.5 \pm 0.547$ & $4 \pm 0.161$ & $60 \pm 2.720$ & $58.33 \pm 1.630$ \\
2 & $6.8 \pm 0.404$ & $8.2 \pm 0.330$ & $2.5 \pm 0.144$ & $120 \pm 9.52$ & $75.00 \pm 1.770$ \\
3 & $9 \pm 0.044$ & $9.2 \pm 0.126$ & $3 \pm 0.042$ & $65 \pm 1.700$ & $69.23 \pm 0.590$ \\
4 & $10 \pm 0.244$ & $10.3 \pm 0.097$ & $3.5 \pm 0.059$ & $85 \pm 2.380$ & $58.82 \pm 1.530$ \\
5 & $7.2 \pm 0.322$ & $7 \pm 0.575$ & $1.5 \pm 0.039$ & $62 \pm 2.312$ & $56.45 \pm 2.020$ \\
6 & $7.2 \pm 0.322$ & $7.5 \pm 0.473$ & $2.2 \pm 0.020$ & $63 \pm 2.108$ & $53.96 \pm 2.522$ \\
7 & $10.5 \pm 0.350$ & $10.2 \pm 0.077$ & $3.3 \pm 0.0183$ & $75 \pm 0.340$ & $74.66 \pm 1.702$ \\
8 & $7.8 \pm 0.200$ & $10.5 \pm 0.138$ & $3.5 \pm 0.059$ & $105 \pm 6.484$ & $67.61 \pm 0.260$ \\
9 & $8 \pm 0.159$ & $11.5 \pm 0.340$ & $3.7 \pm 0.100$ & $85 \pm 2.382$ & $64.70 \pm 0.330$ \\
10 & $7.5 \pm 0.260$ & $11 \pm 0.240$ & $3.2 \pm 2.041$ & $56 \pm 3.537$ & $73.21 \pm 1.406$ \\
11 & $7.8 \pm 0.200$ & $12 \pm 0.444$ & $3.5 \pm 0.005$ & $67 \pm 1.292$ & $61.19 \pm 1.047$ \\
12 & $7.2 \pm 0.322$ & $9 \pm 0.169$ & $2.2 \pm 0.026$ & $42 \pm 6.395$ & $52.38 \pm 2.840$ \\
13 & $7 \pm 0.360$ & $10.2 \pm 0.077$ & $3.6 \pm 0.079$ & $55 \pm 3.741$ & $58.18 \pm 1.660$ \\
14 & $9 \pm 0.044$ & $11 \pm 0.240$ & $3.5 \pm 0.059$ & $60 \pm 2.700$ & $75.00 \pm 1.770$ \\
15 & $9.2 \pm 0.087$ & $10.5 \pm 0.138$ & $3.5 \pm 0.059$ & $120 \pm 9.526$ & $60.02 \pm 1.280$ \\
16 & $10.2 \pm 0.028$ & $8 \pm 0.371$ & $2.5 \pm 0.144$ & $65 \pm 1.700$ & $72.30 \pm 1.220$ \\
17 & $10 \pm 0.249$ & $10.3 \pm 0.097$ & $3.8 \pm 0.120$ & $104 \pm 6.260$ & $68.26 \pm 0.396$ \\
18 & $13.5 \pm 0.963$ & $10.4 \pm 0.118$ & $3.5 \pm 0.059$ & $120 \pm 9.526$ & $75.90 \pm 0.934$ \\
19 & $10.5 \pm 0.351$ & $11.5 \pm 0.342$ & $4.2 \pm 0.202$ & $75 \pm 0.340$ & $69.33 \pm 0.614$ \\
20 & $9.5 \pm 0.146$ & $11.2 \pm 0.281$ & $4 \pm 0.161$ & $85 \pm 2.383$ & $65.88 \pm 0.089$ \\
21 & $9 \pm 0.156$ & $8.2 \pm 0.109$ & $2.2 \pm 0.206$ & $55 \pm 3.741$ & $71.11 \pm 0.089$ \\
22 & $7.5 \pm 0.261$ & $7.8 \pm 0.412$ & $3.5 \pm 0.059$ & $40 \pm 6.800$ & $70.00 \pm 0.751$ \\
23 & $9.8 \pm 0.208$ & $7.5 \pm 0.437$ & $3.5 \pm 0.059$ & $65 \pm 1.700$ & $73.84 \pm 1.535$ \\
24 & $6.8 \pm 0.404$ & $10.2 \pm 0.077$ & $3.2 \pm 2.040$ & $56 \pm 3.537$ & $71.42 \pm 1.041$ \\
Mean & 8.78 & 9.82 & 3.21 & 73.33 & 66.32 \\
\hline & & & & &
\end{tabular}


(0.012\%). Shruti et al. (2013) reported that the linalool content was $0.96 \%$ and Shahin et al. (2012) found that linalool content was $0.348 \%$ using GC-MS. Singh et al. (2010) reported $0.59 \%$ linalool in P. nigrum. Thus, it was found that the linalool content in genotypes 23 and 24 was similar to the findings of Shruti et al. (2013) and Shahin et al. (2012).

The percentage of piperine varied from $0.222 \%$ to $8.473 \%$. The analysis of volatile oil revealed that the piperine content was highest in genotype 2 with $8.473 \%$, followed by genotype 17 with $2.75 \%$. On the contraray, the lowest amount was recorded in genotype 20 with $0.222 \%$. Vasavirama et al. (2014) reported that the piperine content in the fruits of $P$. nigrum was $8.76 \%$ using super critical fruit extraction. Shruti et al. (2013) reported that the piperine content ranged from $2.13 \%$ to $4.49 \%$ using the GC-MS analysis. Chauhan et al. (2008) found that the amount of piperine in P. nigrum seed was $6.00 \%$ using HPLC method. However, in the present study the highest piperine content was $8.473 \%$ which was more than the findings of Shruti et al. (2013) and Chauhan et al. (2008) and on par with the findings of Vasaviram et al.
(2014). Hence, the genotype 2 can be utilized for the piperine extract for many pharmaceuticals and other uses.

\section{Principal component analysis (PCA)}

The principal component analysis revealed that the genotypes $23,7,6,18,10$ and 24 have a positive result having myrecene and linalool content (Fig. 1). Among all these, genotype 23 has the highest amount of myrcene content followed by genotype 18. Genotypes 8, 20, $21,5,11,22$ and 14 have a good amount of $\alpha$-phellandrene. Genotype 8 showed a higher amount of $\alpha$-phellandrene among all the genotypes. Genotypes 2, 16, 9, 19, 1 and 4 were found to have higher amount of piperine. Among them, genotype 2 has the highest amount followed by genotypes 16 and 9. Among the 24 genotypes, genotypes $17,15,13$ and 12 have the lowest amount of all the secondary metabolites and hence these genotypes are considered to be poor.

From the study, it was evident that the genotypes $18,19,2$ and 15 were better in terms of yield parameters. Within these four genotypes, 18
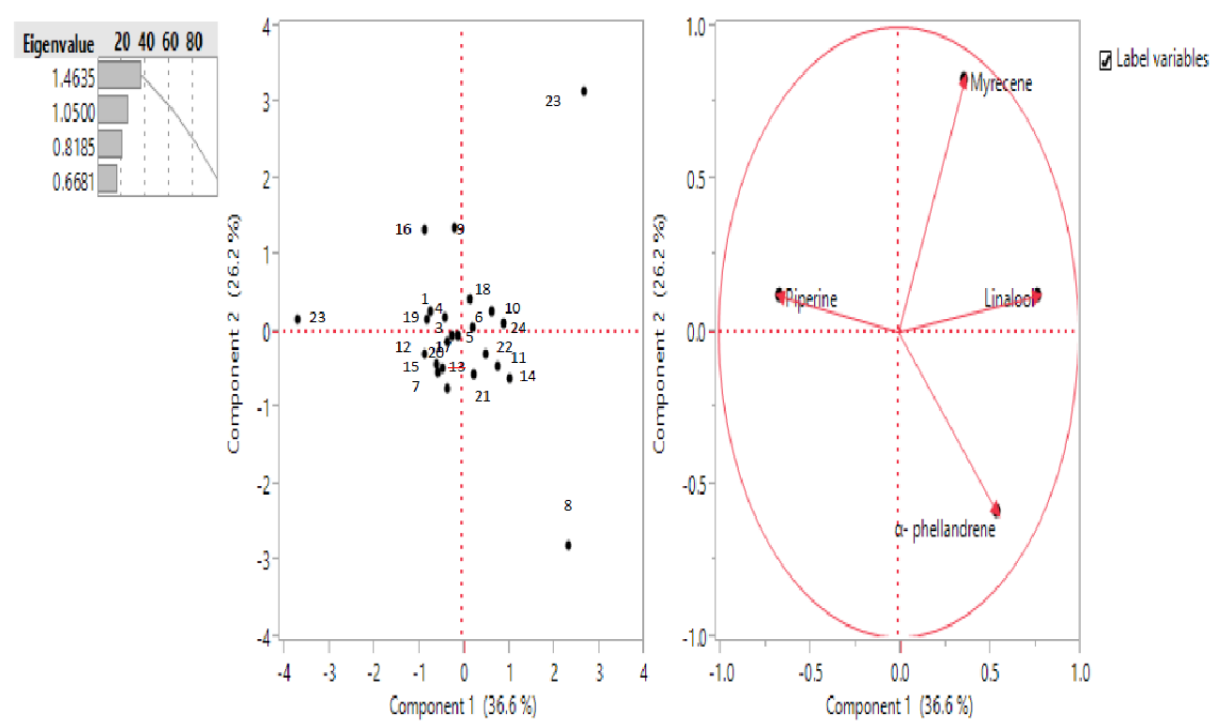

Fig. 1. Principal component analysis of 24 genotypes of black pepper 
Table 3. Comparison between black pepper grown in conventional area and Sikkim

\begin{tabular}{lccl}
\hline Parameter & $\begin{array}{c}\text { Range of values in commercial } \\
\text { varieties grown in conventional } \\
\text { area }\end{array}$ & $\begin{array}{c}\text { Value in the Sikkim genotype } \\
\text { (best genotype) }\end{array}$ \\
\hline Spike length (cm) & $11.6-14.70$ & 13.50 (Genotype 18) \\
Weight of 100 fresh berries (g) & $9.8-11.60$ & 12.50 (Genotype 01) \\
Weight of 100 dried berries (g) & $1.6-3.80$ & $4.20 \quad$ (Genotype 19) \\
No. of flowers/ spikes & $88.0-96.30$ & 120.00 (Genotypes 02,15,18) \\
Fruit set (\%) & $77.2-80.20$ & 75.90 (Genotype 18) \\
Volatile oil (\%) & $1.6-3.20$ & 2.01 & (Genotype 08) \\
$\alpha$-phellandrene (\%) & $1.06-2.87$ & 1.37 & (Genotype 08) \\
Linalool (\%) & $0.21-1.70$ & $0.83 \quad$ (Genotype 23) \\
Myrcene (\%) & $1.76-2.74$ & $2.09 \quad$ (Genotype 23) \\
Piperine (\%) & $2.13-4.49$ & $2.75 \quad$ (Genotype 02) \\
\hline
\end{tabular}

was better for most yield parameters followed by genotype 2 . On the other hand genotypes 8 and 23 were better for quality parameters. Eventhough the genotype 2 was poor in many secondary metabolites, it was the best genotype for the main metabolite piperine. Hence, the study indicates that genotypes 18, 8, 23 and 2 are promising genotypes for commercial exploitation in Sikkim Himalyan region.

\section{References}

Bentham G \& Hooker J D 1880 L Reeve and Co. London. Genera Plantarum 3: 132-133.

Chauhan R, Dwivedi J \& Siddiqui A A 2008 Chemical standardization and quantification of piperine from methanolic extract of Piper nigrum by HPLC method on the basis of isolated markers. Int. J. Chem. Sci. 6: 17261733.

Chen Y S 2013 An investigation on possible occurrence of apomixes in pepper (Piper nigrum). In. Proceeding, $2^{\text {nd }}$ International Conference on Environment, agriculture and food sciences (ICEAFS'2013) May 6-7 Kuala Lumpur (Malaysia).

Epstein W W, Netz D F \& Seidel J L 1993 Isolation of piperine from black pepper. J. Chem. Ed. 70: 598-599.

Jirovetz L, Buchbauer G, Ngassoum M B \& Geissler
M 2002 Aroma compound analysis of piper nigrum and piper guineense essential oils from Cameroon using solid phase microextraction-gas chromatography, solidphase microextraction - gas chromatographymass spectrometry and olfactometry. J. Chromatogr. A. 976: 265-267.

Krishnamurthy K S, Ankegowda S J, Srinivasan V \& Hamza S 2013 Influence of carbohydrates, mineral nutrients and plant hormones in alternate bearing of black pepper (Piper nigrum L.). American J. Plant Sci. 4: 19601967.

Prasannakumari S, Nybe E V, Sujatha V S \& Prabhakaran P V 2001 Survey, evaluation and identification of black pepper cultivars. J. Trop. Agric. 39: 9-12.

Rmili R, Ramdani M, Ghazi Z, Saidi N \& El Mahi B 2014 Composition comparison of essential oils extracted by hydrodistillation and microwave-assisted hydrodistillation from Piper nigrum L. J. Mater. Environ. Sci. 5: 1560-1567.

Sasikumar B, Saji K V \& Johnson K George 2007 Spike proliferation in black pepper (Piper nigrum L.). Fruits. 62: 325-328.

Shahin A, Naher S, Abukawsar M D \& Roy S K 2012 Comparative studies on physicochemical properties and GC-MS analysis of volatile oil of the two varieties of the black pepper (Piper nigrum Linn.). Int. J. Pharm. Sci. Res. 2: 67-70. 
Shruti D, Zachariah T J, Leela N K \& Jayarajan K 2013 Correlation between chemical profiles of black pepper (Piper nigrum L.) var. Panniyur -1 collected from different locations. J. Med. Plants Res. 7: 2349-2357.

Singh H, Kumoro A C \& Hasan M 2010 Extraction of sarawak black pepper volatile oil using supercritical carbon dioxide. Arabian J. Sci.
Eng. 35: 7-16.

Trelease W \& Yuncker T G 1950 The Piperaceae of Northern South America, University Illinois, USA.

Vasavirama K \& Upenders M 2014 Piperine: A valuable alkaloid From Piper species. Int. J. Pharm. Pharm. Sci. 6: 34-38. 